\title{
An evidence-based technological caregiver skill building intervention for dementia family caregivers: pilot study
}

\author{
Carol J Farran ${ }^{1 *}$, Peter Zurawski ${ }^{2}$, Ben R Inventor ${ }^{3}$ Janie Urbanic $^{4}$ and Olimpia Paun ${ }^{5}$ \\ ${ }^{1}$ Emeritus Professor and The Nurses Alumni Association Endowed Chair in Health and the Aging Process, Rush University College of Nursing, Adult Health and \\ Gerontological Nursing, 600 South Paulina Street, Armor Academic Center, 1080 AAC, Chicago, IL, USA \\ ${ }^{2}$ Vice-President, Grand Marketing Solutions, Ashley Circle, Suite 212, Libertyville, IL, USA \\ ${ }^{3}$ Assistant Professor, Rush University College of Nursing, Adult Health and Gerontological Nursing, 600 South Paulina Street, Armour Academic Center, 1080 \\ AAC, Chicago, IL, USA \\ ${ }^{4}$ Research Coordinator, Rush College of Nursing, 600 South Paulina Street, Suite 1080 Armor Academic Center, Chicago, IL, USA 60612 \\ ${ }^{5}$ Associate Professor and Inaugural Kellogg Faculty Scholar, Rush University College of Nursing, Department of Community, Systems, and Mental Health, 600 \\ South Paulina Street, Suite 1080 Armor Academic Center, Chicago, IL, USA
}

\begin{abstract}
Family caregiving is a growing public health concern and caregivers of persons with Alzheimer's disease or other related dementias (ADRD) need appropriate, timely, and ongoing education and support to successfully meet their caregiving responsibilities. Well-designed interventions can significantly reduce risk concerning caregiver mental and physical health, and improve care recipient outcomes. Few interventions are translated into everyday practice; and most rely on in-person, professionally-led delivery methods, making them inaccessible to many family caregivers.

The product developed and tested in this pilot study included six evidence-based Caregiver Skill Building Intervention (CSBI) modules, available via a web-based online format for ADRD caregivers. On-demand interactive training modules made up an integrated web-based product that taught family caregiver skills concerning how to care for their impaired family member. Product strengths include: a) an evidence-based intervention, developed from a prior group-based randomized clinical trial (RCT); b) a focus on caregiver management skill, rather than merely teaching facts; c) an interactive approach, enabling caregivers to apply information to realistic scenarios and receive immediate feedback to their responses; d) content which addresses key caregiving topics; and e) a convenient approach, available 24 hours/day/7 days/week from any location with internet access.

The project enrolled 100 family caregivers and established feasibility of translating an RCT group intervention to an individualized web-based format. Caregivers positively evaluated this eLearning process $(n=53)$; significantly increased caregiving skill at 6 - and 12 -weeks, $(p=0.01$ and 0.05 , respectively); and improved caregiver depressive symptoms $(p=0.01)$ and positive affect $(p=0.05)$ at six weeks.
\end{abstract}

\section{Introduction}

\section{Family caregivers}

More than 5 million Americans of all ages have been identified as having Alzheimer's disease or a related dementia (ADRD). Total 2016 costs for health care, long-term care and hospice for persons with ADRD were estimated to be $\$ 236$ billion. Additional "costs" of caring for persons with ADRD are generally assumed by unpaid caregivers [1]. More than 15 million Americans provide unpaid care for persons with ADRD, ranging from activities of daily living, personal care needs, shopping and transportation. It is estimated that the 18.1 billion hours of care provided by family members or others, represents a contribution of $\$ 221.3$ billion (in 2015 dollars) [1]. Main reasons caregivers decide to provide direct care and assistance, is so they can: 1) keep their family member at home $(65 \%) ; 2$ ) be in closer proximity and see how well their family member is doing (48\%); and 3) fulfill their obligation as a spouse or partner (38\%) [1,2].

The "unpaid cost" of caring for family members of persons with dementia, is usually provided by women (66\%), who are 65 years or older, married, non-Hispanic white (66\%), who report providing 21-60 hours of care/week; and are more likely to live with their partner or are in a long-term relationship (>66\%) $[3,4]$. These women are generally well-educated with $>40 \%$ having a college degree or more education. They are more likely to be non-Hispanic white $(>66 \%), 10 \%$ are African American, 8\% are Hispanic and 5\% are Asian. Over 40\% have household income of $\leq \$ 50,000$ [4]. The majority take care of their aging parents (55\%) [5] and live with their care recipient in the community. Surveys have noted that $23 \%$ of ADRD caregivers are in the "sandwich generation," in that they care for an aging parent and their children $<18$ years [2].

Correspondence to: Carol J Farran, DNSc, RN, FAAN, Emeritus Professor and The Nurses Alumni Association Endowed Chair in Health and the Aging Process, Rush University College of Nursing, Adult Health and Gerontological Nursing, 600 South Paulina Street, Armor Academic Center, 1080 AAC, Chicago, IL, USA, Tel: (708) 386-5395, Fax:312-942-3287; E-mail: Carol_J_Farran@rush.edu

Key words: dementia family caregivers, evidence-based intervention, web-based technology

Received: January 03, 2017; Accepted: January 20, 2017; Published: January 23, 2017 
Responsibilities often assumed by family caregivers include: assisting with instrumental activities of daily living (IADL's) (i.e., household chores, shopping, preparing meals, providing transportation, arranging for healthcare appointments, managing finances, legal affairs, and answering the telephone). They also provide support for taking medications, including reminders or direct medication administration; and monitoring adherence to treatment interventions for dementia or other health concerns. Assistance is also provided for personal activities of daily living (PADL), including bathing, toileting, grooming, feeding, assisting with ambulation, transferring from bed to chair, using the toilet and managing incontinence. A major concern that may cause stress for caregivers includes managing behavioral symptoms of dementia, such as aggressive behaviors, wandering, depressive mood, agitation, anxiety, repetitive behaviors and nighttime wakefulness. Caregivers also find support services and supervise in-home help; and manage "getting through the day," by addressing family issues that may cause stress or disagreements concerning care [1].

Generally, female caregivers report higher levels of burden than male caregivers, which may be due to their spending more time caregiving than men, taking on more caregiving tasks, or caring for someone with more behavioral problems [1]. Dementia caregivers report substantial financial, emotional and physical difficulties with caring for another person [3]. Fifty-nine percent of ADRD caregivers note that the emotional stress of caregiving is high or very high [2]. Approximately $40 \%$ report depressive symptoms, compared with $5-17 \%$ of similar non-caregivers [6,7]. Caregivers (22\%) report difficulty with medical/nursing tasks required of them [8]. But in a 2014 Alzheimer's Association poll, caregivers often felt they had "no choice" than to provide care. This same poll found that women caring for both young children and a family member with dementia, felt that caring for the person with ADRD was more challenging than caring for their children $(53 \%)[2,8]$. Dementia family caregivers also noted that the year before their care recipient's death, they felt they were 'on duty' 24 hours/day; and many felt that caregiving was very stressful (59\%). A study of end-of-life care noted that $72 \%$ of family caregivers experienced relief when the person with dementia died [9].

Caregiver emotional burden often translates into physical health changes and may include: increased caregiver susceptibility to disease and health complications ( $38 \%$ indicated that stress of dementia care was substantial) [2]. Other changes in health indicators included: increased sleep disturbances and physical strain (28\% versus $17 \%$ ) compared to non-caregivers. A total of $74 \%$ of Alzheimer's caregivers said they were "somewhat to very concerned about their health" and that caregiving made their health worse ( $41 \%$ increased odds compared to $2 \%$ in non-caregivers). Other studies suggest that caregiving may have a positive effect on keeping older adults more physically active than non-caregiving counterparts [10].

Higher levels of physiological changes have also been reported in caregivers of spouses with ADRD, as opposed to non-caregivers, increasing their risk of developing chronic conditions including elevated biomarkers of cardiovascular disease risk and changes in kidney function [11-14]. Caregivers of persons with ADRD, compared to married non-caregivers have shown physiological changes that may be associated with declining physical health, such as high levels of stress hormones [15], reduced immune function [16], slow wound healing [17], increased incidence of hypertension, coronary heart disease, and increased risk for cardiovascular disease [18-20]. In 2014, estimated health care costs associated with dementia caregiving were $\$ 9.7$ billion [1]. Additional studies noted that caregivers were more likely to be hospitalized and make emergency room visits if their care recipient was depressed, had low functional status or behavioral disturbances [14].

\section{Caregiver interventions}

Research suggests that the process of family caregiving may last more than 20 years, suggesting that a variety of caregiver interventions are greatly needed [21]. Over the past five decades, numerous family caregiver interventions have been tested, with improved designs and approaches being used. Generally, however, these studies have been guided by the Stress Process model and focused on moderate stage dementia. Initially during the 1960's to 1990's, interventions focused on caregiver education and support and were designed to reduce caregiver distress and avoid care-recipient nursing home placement. Stressors focused on burden and depressive symptoms. Study findings were mixed, with small to null effects, but individualized intervention approaches had better outcomes compared to group interventions [22].

During early to late 1990's, more rigorous randomized clinical trials (RCTs) were tested and resulted in stronger outcomes and longterm effectiveness. Support and counseling interventions decreased depressive symptoms in spouse caregivers and delayed care receiver nursing home placement. Limitations of this phase included lack of inclusion of diverse caregiver participants, greater emphasis on spousal caregivers, lack of documentation concerning intensity of intervention dose, specific intervention components, limited study designs and a focus on families of persons with mid-stage dementia [21].

During the late 1990's to early 2000's, more robust randomized controlled trial (RCT) designs and more diverse caregiver samples were used, but effect sizes still generally, remained small. The NIH REACH I initiative (Research for Enhancing Alzheimer's Caregiver Health) tested a broader range of intervention approaches, including psychological group and individual counseling skills, behavior management training, problem solving, technologically focused education, environmental modification and supportive programs [9]. These studies included more diverse multicultural samples, more varied caregiver/care recipient relationships; and used more specific treatment fidelity protocol, specific manuals, had greater dose intensity and greater caregiver participation, with increased focus on caregiver skills, mastery, efficacy and mental health [21].

Building upon REACH I studies, REACH II studies used five geographically diverse sites and tested single multicomponent interventions that focused on: 1) decreasing depressive symptoms, 2) decreasing burden, 3) improving self-care; 4) enhancing social support, and 5) managing behavioral symptoms. Tailoring interventions to individual profiles, needs and caregiver concerns was a unique component of these interventions. These studies were effective in increasing multicomponent quality of life for Hispanic, white and African American spousal caregivers; decreasing prevalence of depressive symptoms, but were not significant in decreasing care recipient nursing home placement at 6 months [21,23-24].

In the fourth, and present phase of caregiver intervention research (2006 to present) there has been greater focus on the full continuum of dementia (i.e., early phase to end-of-life) [21], as well as greater use of innovative technology [25], multidisciplinary teams, collaborative primary care management models [21,26-27], and dyadic focused interventions [28]. Nonetheless, continuing challenges with ADRD family caregiver interventions need to be addressed, such as translating these interventions and adapting them for integration into a care delivery setting and testing them on a larger scale [21]. 


\section{Technologically-based caregiver interventions}

More recently, attention has been given to developing and testing technologically based interventions for dementia caregivers. Internet and social media have rapidly developed and facilitated caregiver access to new materials, as well as 'intelligent' systems that may monitor kitchen and personal care [29]. Organizations frequented by caregivers have developed and made some of these materials available on their websites (i.e., Alzheimer's Association, National Alliance for Caregiving, Administration on Aging, Family Caregiving Alliance and others) [30].

A variety of services have been tested with family caregivers, including an intervention that has monthly telephone training sessions that focus on service use [31]; the Caregivers' Friend: Dealing with Dementia that provides web-based materials, written and video materials tailored to the individual [32] ; an Online Stress Management Training Program where caregivers exchange materials with each other, receive weekly psycho educational sessions, have access to online coaches and question-and-answer sessions at established times [33]. These technologically-based studies have had mixed findings, with some noting positive changes in decision-making confidence; improvement in health status, burden, mental health and depressive symptoms; well-being, confidence, self-efficacy, stress appraisal, selfcontrol and goal attainment [30]. Other technologically-based studies have not consistently found significant post intervention changes in mental health outcomes such as depressive symptoms and anxiety [3436]. One study that reported no drop outs used a professionally led, live-streaming video online group intervention, where caregivers could support and see each other 'live' [36]. Study limitations have included small sample sizes, low retention rates and short interventions; and absence of randomized controlled trials.

Additional studies have tested technologies designed to help monitor and support persons with dementia in performing kitchen and personal care tasks. Persons most willing to use these technologies included younger caregivers, with medium-to high income, those caring for a person with Alzheimer's disease, with decreased hours of care/week, with positive attitudes towards technology and greater experience using technology [29]. Willingness to pay for these technologies was also examined with $20 \%$ of caregivers not willing to pay anything for kitchen and self-care technologies. For those willing to pay something, the mean amount was approximately $\$ 50 /$ month for monitoring technologies; and $\$ 70 /$ month for technologies that monitored and provided some assistance with personal care tasks [29].

\section{Translation of a prior randomized controlled trial}

A randomized controlled trial (R01 NR04561), developed and tested by investigators, examined two interventions: Caregiver Skill Building (CSB: Treatment Group) versus an Information and Support Oriented (ISO: Control Group Intervention). Participants who completed the in-person group-based CSB treatment intervention, reported a significant decrease in depressive symptoms and decreased distress with difficult dementia behaviors $[37,38]$. Qualitative analyses of group summaries from each intervention was also conducted [39-41]. Combined quantitative and qualitative data guided the development and translation of the six web-based modules during this translational phase. Content for the final STTR (Small Technology Transfer Research) modules was based on integration of key information from the combined CSB and ISO interventions; and resulted in the following modules: 1) Using Person Centered Care; 2) Understanding Dementia; 3) Implementing Activities of Daily Living; 4) Managing Behavioral
Symptoms of Dementia; 5) Caring for Self; and 6) Finding and Using Help.

\section{Study purpose and aims}

The purpose of this pilot study was to develop and test six Caregiver Skill Building Intervention (CSBI) web-based modules translated from an original randomized clinical trial and: 1) Examine CSBI modules for their ease in intervention implementation and caregiver evaluation of module content; 2) Appraise preliminary CSBI outcomes; and 3) Determine technological challenges in implementing the web-based CSBI.

\section{Materials and methods}

\section{Recruitment and enrollment of subjects}

Most subjects were recruited from the National Institute on Aging (NIA) Rush Alzheimer's Disease Center (RADC), Research Core (58\%); Community Agencies (19\%); additional NIA Alzheimer's Disease Centers (11\%); the Rush Without Warning (WOW) program for caregivers of persons with young onset Alzheimer's disease (YOAD) or a related dementia (11\%); and a Web-based agency (1\%) (Table 1). The study was approved by the Rush University Medical Center Institutional Review Board. Each subject electronically signed their consent form prior to engaging in the research phase.

A total of 133 caregivers were referred to the study from community-based sites; 121 caregivers were screened, 118 were initially found to be eligible (89\%) (Figure 1). Eligibility criteria included that the caregiver: was living with care-recipient in a home-based setting; regularly responded to study e-mails and phone calls; had access to and was familiar with operating a computer, IPhone, IPad or other similar device, that used e-mail and web-based communication (16\%). Caregivers not meeting enrollment criteria were not eligible for the study. A total of 92 caregivers consented and enrolled in the study (69\%); $8 \%$ completed $\leq 5$ modules; $61 \%$ completed all 6 modules; $60 \%$ completed the 6-week (second) assessment; and $40 \%$ completed the 12 week (third) assessment.

\section{Clinical outcome measures}

Four caregiver self-report outcome measures included: Caregiver Skill Building, Burden, Depressive Symptoms, and Positive Affect. The 11-item Caregiver Skill Building measure determined how skilled caregivers felt they were in responding to care recipient's strengths, needs, requests, abilities, making choices, making each day fun, involving relative in activities, using 'white lies,' keeping things

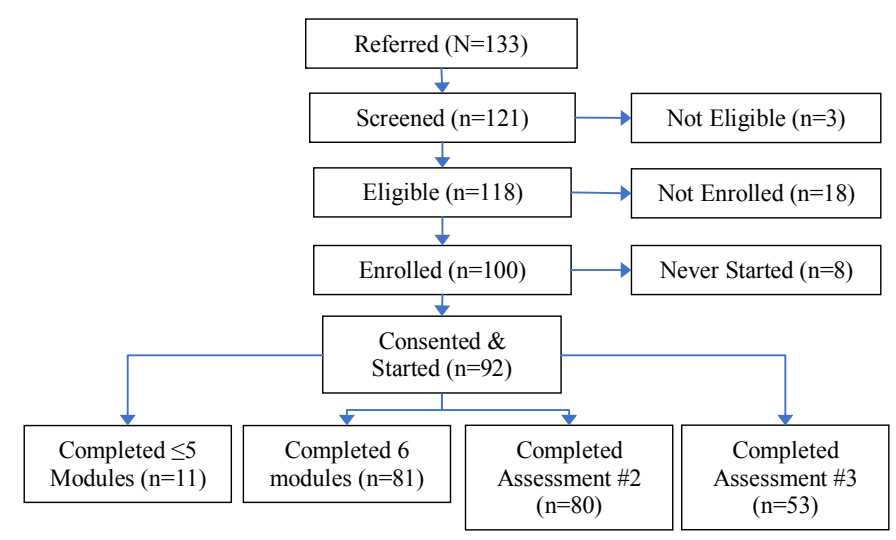

Figure 1. CSBI Consort Table. 
organized and using humor [42]. Acceptable psychometric properties of this measure have been noted. Responses ranged from $1=\mathrm{I}$ do not do this very well to $3=\mathrm{I}$ do this very well (Range 11-33). Quantitative methods examined intervention mean outcomes and internal consistency at baseline, 6- and 12-weeks (Table 2).

An 11-item measure of Burden focused on feelings of 'no time' for self, poor health, social activities, feeling isolated and alone, unable to care for relative much longer, losing control of their life, feeling very tired, fitting things into their life, unpredictability, inability to determine how days are spent and feeling trapped. Responses ranged from $0=$ never to $4=$ nearly always and determined how burdened caregivers felt with providing care (Range 0-44) [43].

The 10-item measure of depressive symptoms examined feelings that caregivers reported having in the past week, using responses of $0=$ no and $1=y e s$. Items included feeling: depressed, everything took an effort, sleep was restless, happy, lonely, others were unfriendly, enjoyed life, sad, felt people disliked me, and could not 'get going' (Range 0-10) [44].

Positive affect was assessed using 10 items from the PANAS measure with responses that ranged from $1=$ very slightly/not at all to $5=$ extremely. Items focused on whether caregivers felt interested, excited, strong, enthusiastic, proud, alert, inspired, determined, attentive, and active (Range 10-50) [45].

\section{Intervention feasibility and program evaluation}

Five quantitative program evaluation components included: 1) Content and organization, rated content as being logical, understandable, interesting, well-paced, essential, modules being a

Table 1. Recruitment by provider type, subject number and percent.

\begin{tabular}{|l|c|c|}
\hline \multicolumn{1}{|c|}{ Providers } & $\#$ & \% \\
\hline Rush Alzheimer's Disease Center & 70 & 58 \\
\hline Community Agencies & 24 & 19 \\
\hline Other Alzheimer's Disease Centers & 13 & 11 \\
\hline Other Rush Clinical Sites & 13 & 11 \\
\hline Web-Based Agency TOTAL & 1 & 1 \\
\hline \multicolumn{2}{|c|}{ TO1 } & $\mathbf{1 0 0}$ \\
\hline
\end{tabular}

Table 2. Clinical outcome measures: pairwise mean differences between B-to-6 and B-to12 weeks and standardized coefficient alphas at B, 6 and 12-weeks.

\begin{tabular}{|c|c|c|c|c|}
\hline Clinical Outcome Variables & $\begin{array}{l}\text { Study } \\
\text { Time }\end{array}$ & M(SD) & $p$ & $a$ \\
\hline \multicolumn{5}{|l|}{ Caregiver Skill Building } \\
\hline & B & $25(5)$ & & 0.77 \\
\hline & 6-wk & $29(3)$ & 0.01 & 0.60 \\
\hline & $12-w k$ & $28(6)$ & 0.05 & 0.93 \\
\hline \multicolumn{5}{|l|}{ Burden } \\
\hline & $\mathrm{B}$ & $1.8(0.75)$ & & 0.85 \\
\hline & 6-wk & $1.7(0.67)$ & 0.45 & 0.85 \\
\hline & 12-wk & $1.7(0.63)$ & 0.45 & 0.83 \\
\hline \multicolumn{5}{|l|}{ Depressive Symptoms } \\
\hline & $\mathrm{B}$ & $4(2)$ & & 0.55 \\
\hline & 6-wk & $4(2)$ & 0.01 & 0.49 \\
\hline & $12-w k$ & $4(2)$ & 0.06 & 0.51 \\
\hline \multicolumn{5}{|l|}{ Positive Affect } \\
\hline & B & $32(7)$ & & 0.90 \\
\hline & 6-wk & $35(6)$ & 0.05 & 0.87 \\
\hline & $12-w k$ & $34(9)$ & 0.51 & 0.95 \\
\hline
\end{tabular}

Note. $\mathrm{B}=$ Baseline $\mathrm{N}=100$ (75\%); 6-wk $\mathrm{n}=81$ (61\%); 12-wk n=53 (40\%).

$a=$ Standardized Cronbach Coefficient Alpha fun way to learn, and whether the modular approach to learning was preferable to participating in a workshop. Responses ranged from $1=$ strongly agree to $5=$ strongly disagree with lower scores being more positive (Range 5-25). 2) Audiovisual quality included 5 items using the same item response pattern noted above (Range 5-25).3) Relevance of family examples in each module, included whether caregivers increased understanding of their impaired family member, the intervention made modules more interesting, and represented individual ethnic/ cultural groups within each module (Range 3-15). 4) Individual module content assessed helpfulness of each topic and whether module topics included: Alzheimer's disease and related dementias, person-centered care, behavioral symptoms, activities of daily living, responding to personal stress, whether caregivers learned new approaches, or accessed websites and attachments included in each module (Range 7-35) [46]; 5) Number of persons using telephone support (Range 0-17); and 6) Caregiver open-ended responses to what was 'most helpful 'and 'future recommendations' concerning the CSBI were summarized using mixed-methods including both quantitative and qualitative content analysis of caregiver responses [47].

\section{Results}

\section{Baseline socio-demographic characteristics}

Most enrolled caregivers $(n=92)$ were female $(82 \%)$, ranged in age from 20 - 84 years, with $50 \%$ being $\geq 60$ years old. The majority was White (59\%), followed by African American (39\%), Hispanic or Asian (2\%); and had English as their first language (99\%). Nearly half were spousal caregivers (49\%), followed by being an adult child/child-in-law/other relative $(46 \%)$, with only $6 \%$ being non-family caregivers. The majority was married/living with their partner $(67 \%)$, well-educated $(87 \%$ $\geq$ college or more advanced education), but were not employed (56\%). Of those working, the most worked 40-49 hours/week (17\%). Impaired relatives generally were female (57\%); with $19 \%$ being $\leq 60$ years old. Most relatives had received care for $1-4$ years (59\%), while $24 \%$ had received care for 5-19 years, but only $17 \%$ had received care for $\leq 1$ year.

\section{Clinical outcomes}

Caregiver Skill Building means significantly changed from Baseline to 6-weeks ( $p=0.01$ ); and decreased slightly from 6 to 12 weeks $(p=0.05)$. Cronbach's coefficient alpha for this measure was high at only 12 -weeks $(a=0.93)$ (Table 2). Burden outcomes were low at baseline and did not significantly change at either 6 - or 12 -weeks $(p=0.45)$. Cronbach's coefficient alpha for burden was consistently high at all three time points $(a=0.83-0.85)$. Depressive symptom means did not numerically change at any time point but indicated significant change from Baseline to 6-weeks $(p=0.01)$ and approached significance from 6- to 12-weeks $(p=0.06)$. Depressive Symptom alpha was low at all time points $(a=0.49-0.55)$. Positive affect improved three points from baseline to 6-weeks $(p=0.05)$, and decreased slightly, but not significantly, from 6to 12-weeks $(p=0.51)$. Cronbach's coefficient alphas for Positive Affect were consistently $\geq 0.87$ at all three time points.

\section{CSBI program evaluation and feasibility}

Quantitative and qualitative approaches examined CSBI feasibility and program evaluation. Quantitatively, caregivers positively evaluated all aspects of the CSBI with no significant change in their evaluation between 6- and 12-weeks (Table 3). Qualitatively, caregivers reported four intervention aspects that were most helpful (Table 4): 1) learning about themselves and caregiving; 2) learning about resources and approaches to care; 3) learning more about specific approaches to 
Table 3. Quantitative program evaluation by focus: number of items, possible range, by week and mean differences between 6- and 12-weeks.

\begin{tabular}{|c|c|c|c|c|c|}
\hline $\begin{array}{c}\text { Evaluation } \\
\text { Focus }\end{array}$ & $\begin{array}{c}\text { \# of } \\
\text { Items }\end{array}$ & $\begin{array}{c}\text { Possible } \\
\text { Range }\end{array}$ & Week & M (SD) & $p$ \\
\cline { 1 - 5 } Content and Organization & 7 & $7-35$ & 6 & $12.6(3.9)$ & \multirow{2}{*}{0.30} \\
\cline { 1 - 5 } Audio Visual Quality & 5 & $5-25$ & 6 & $9.7(5.1)$ & \multirow{2}{*}{0.62} \\
\hline Relevance & 3 & $3-15$ & 6 & $5.2(2.4)$ & \multirow{2}{*}{0.32} \\
\hline Quality of Modules & 7 & $7-35$ & 12 & $5.6(2.5)$ & \multirow{2}{*}{0.22} \\
\hline
\end{tabular}

Note. Possible Range: $1=$ strongly agree to $5=$ strongly disagree

Table 4. Most helpful qualitative intervention components: By total number of comments and percentages by category.

\begin{tabular}{|l|c|c|}
\hline Categories & $\#$ & $\%$ \\
\hline $\begin{array}{l}\text { Learning about Myself } \\
\text { Affirming that I'm doing the right thing, I'm not alone in this } \\
\text { Importance of being informed } \\
\text { Putting things into perspective }\end{array}$ & 40 & 28 \\
\hline $\begin{array}{l}\text { Learning about Resources/Approaches } \\
\text { Good information and resources } \\
\text { Realistic scenarios } \\
\text { Easy to understand \& follow }\end{array}$ & 37 & 26 \\
\hline $\begin{array}{l}\text { Specific Approaches } \\
\text { Problem solving strategies/techniques } \\
\text { Practical solutions } \\
\text { How to be a better caregiver } \\
\text { Person-centered care module }\end{array}$ & 34 & 24 \\
\hline $\begin{array}{l}\text { Learning about Care Recipients \& Their Needs } \\
\text { What to expect as the disease progresses } \\
\text { Behaviors are due to the disease } \\
\text { Information about the disease }\end{array}$ & 31 & 22 \\
\hline TOTAL & $\mathbf{1 0 0 \%}$ & $\mathbf{1 4 2}$ \\
\hline
\end{tabular}

Table 5. Participant recommendations for intervention improvement: By total number of comments and percentages by category.

\begin{tabular}{|c|c|c|}
\hline Categories & \# & $\%$ \\
\hline $\begin{array}{l}\text { Additional Needed Content } \\
\text { Early stage \& early onset dementia } \\
\text { More examples of all disease situations } \\
\text { More on difficult behaviors } \\
\text { Address more complex issues } \\
\text { More about end-of-life planning }\end{array}$ & 87 & 43 \\
\hline $\begin{array}{l}\text { Affirmation of the Program/No recommendations } \\
\text { Information well done/well organized } \\
\text { Easy to follow and understand } \\
\text { Wouldn't change a thing }\end{array}$ & 83 & 41 \\
\hline $\begin{array}{l}\text { Computer/Technical Issues } \\
\text { Graphics did not function properly on iPhone } \\
\text { No need to repeat instructions in each module } \\
\text { Pace too slow } \\
\text { Challenging for my limited computer skills }\end{array}$ & 28 & 13 \\
\hline $\begin{array}{l}\text { Desired Personal Contact } \\
\text { Make contact with participants } \\
\text { Host group sessions }\end{array}$ & 6 & 3 \\
\hline TOTAL & 204 & 100 \\
\hline
\end{tabular}

caregiving, and understanding more about person-centered care; and 4) learning more about the disease and their care recipients' needs, disease progression, and understanding that behaviors were part of the disease.

Caregivers provided three qualitative recommendations for CSBI improvement, and one additional affirmation (Table 5). They suggested that the intervention: 1) needed additional content about early stage and early onset dementia, more examples of disease situations and difficult or complex behaviors, as well as more information about end-of life planning (43\% of responses); 2) selected caregivers experienced some computer/technical issues ( $13 \%$ of responses); and 3 ) a small percentage of comments (3\%) expressed desire to have personal contact with other caregiver participants or to have group sessions with a group leader/ clinician who could help to address some of their individual concerns. Caregivers made 17 phone contacts with organizations such as the Alzheimer's Association, AARP or other caregiving organizations to discuss their unmet needs (data not shown); 4) On the other hand, concerning recommendations, almost the same percentage affirmed the intervention and had no recommendations (41\% of responses), suggesting that the information was well organized and presented, easy to follow and understand, and that they "wouldn't change a thing."

Caregivers and research staff experienced some challenges in the feasibility of addressing technological aspects of this study, namely (Table 6): 1) having consistent access to computer links to open modules; generally these links were found in caregiver's spam;2) in some cases, modules did not function properly when caregivers used their iPad or tablet, or IPhone/smart phone; sometimes browsers quit before caregivers completed their module, or 6- and 12-week assessments; some caregivers were unable to advance the module, or were unable to have their answer to a question be accepted. When they experienced these issues, caregivers contacted the Research Coordinator who assisted them to address the issue or contacted the small business for technological assistance to further resolve these issues. Generally, these issues were easily resolved in working with technological computer staff, but for some caregivers, these challenges were associated with caregiver frustration and eventual study withdrawal.

\section{Discussion, conclusions and recommendations}

Participants were similar to other caregiving groups where the majority was female, predominantly white (59\%), but had nearly 40\% representation from African American family caregiver, which reflects percentages of African Americans found in Chicago [48]. This sample had nearly equal representation of spousal /adult child and other relatives. It was a well-educated sample, where less than half were still employed, but with a small percent working from 4049 hours/week. Most care recipients were female; with nearly $20 \%$ of caregivers being less than 60 years old, likely due to our recruitment from the Rush Without Warning group of persons with young-onset dementia; and the $17 \%$ of caregivers who cared for their relative less than one year. Caregivers were primarily referred to the study through the Rush Alzheimer's Disease Center and the Rush Without Warning Program. Additional referrals came from community agencies and three additional nationally based Alzheimer's Disease Centers, with only one self-referral from a caregiver website. This lack of response from existing websites is possibly due to few caregivers using websites, or the short turn-around time that caregivers had to respond to study

Table 6. Caregiver technological challenges.

\begin{tabular}{|l|c|c|}
\hline Categories & $\#$ & $\%$ \\
\hline $\begin{array}{l}\text { CG Did not receive email/module links } \\
\text { Found in spam } \\
\text { Link did not work/no link in email }\end{array}$ & 23 & 66 \\
\hline $\begin{array}{l}\text { Modules did not function properly } \\
\text { iPad/tablet } \\
\text { IPhone/smart phone }\end{array}$ & 12 & 34 \\
\hline TOTAL & $\mathbf{3 5}$ & $\mathbf{1 0 0}$ \\
\hline
\end{tabular}


recruitment requests.

The major focus of this 12-month STTR pilot study was to develop and test a skill-based technological intervention with family caregivers of persons with ADRD. Study strengths included its evidencebased translational approach; its focus on a web-based skill building intervention that developed modules which emphasized basic content where family caregivers need skill development: 1) Using Person Centered Care; 2) Understanding Dementia; 3) Implementing Activities of Daily Living; 4) Managing Behavioral Symptoms of Dementia; 5) Caring for Self; and 6) Finding and Using Help. The study used a short and simple quantitative measurement strategy that focused on caregiver skill development, burden, depressive symptoms, and positive affect. Caregivers demonstrated significant improvement in caregiver skill at 6- and 12-weeks; a slight improvement in depressive symptoms at 6 weeks; and an improvement in positive affect at 6 -weeks. Caregiver burden scores were low and showed no change over 12-weeks. Twelveweek data should be cautiously interpreted as the sample size was small at this point in the study $(\mathrm{n}=53)$.

Both quantitative and qualitative data were used for program evaluation. Caregivers indicated high to moderately positive scores for quantitative evaluation of content and organization, audio visual quality, intervention relevance and quality of modules (i.e., lower scores indicated greater positive evaluation). Qualitative program evaluation was more instructive concerning areas for future intervention development, where caregivers noted learning more about: themselves, resources and approaches; and about specific approaches to care and being a better caregiver; as well as learning more about their care recipient, the disease, behaviors and what to expect in the future. Caregiver recommendations for future program development included the need for more information about the total scope of dementia (i.e., content on early stage/early onset dementia, attention to more difficult behaviors and complex issues, and end-of-life planning). Caregivers expressed the need for more personal contact with other caregivers and/ staff via telephone or skype. Other technologically-based intervention research has noted that professional contact and caregiver involvement eliminated caregiver attrition and increased intervention satisfaction [36].

Caregivers and research staff faced several challenges in implementing this study including: subject recruitment and retention, computer skill of caregivers and research staff, and off-site technological support. Study recruitment and retention of caregivers was complex. Although caregivers initially met study criteria, additional issues emerged as the study progressed. After determining that 118 caregivers were eligible, 18 of these caregivers never enrolled due to not responding to emails or phone calls encouraging them to enroll, their emails were returned to the study office, one caregiver put the study on his/her 'no contact' list and one person said, after initial assessment, that $\mathrm{s} / \mathrm{he}$ did not have email. These comments suggest some reluctance towards study participation and absence of full-disclosure upon initial study screening. In the future, more attention should be given to exploring caregiver's 'technological availability and readiness' to participate in this type of study; their level of 'knowledge and practical expertise' concerning dementia-related content; and also, the benefits of having regular contact with dementia care experts and/or communication with other caregivers [36].

With the estimated 15 million of Americans who provide care to family members with ADRD and the long-term effects of the disease, it is imperative to continue to design and test easily accessible interventions that maintain the functional health of the impaired family member, as well as their own health [1]. Although older adults lag behind younger Americans concerning adoption of technology, an estimated $77 \%$ use a cell phone and 59\% use the internet [49]. A web-based intervention such as the one tested in this pilot study, provides greater intervention access to older adult caregivers, than existing in-person caregiver group interventions. Limitations of this study included the short duration of 12-months for study development and implementation, and underlying issues concerning participant attrition.

Future directions should include: 1) web-based caregiver content and assistance that enables caregivers to link with and access existing organizations that have caregiver-related content; 2) RCTs that test more than one technologically-based treatment group and extend time to follow-up [50]; 3) more intentional screening of caregivers for technological savvy; 4) incorporating a caregiver technological 'orientation' before beginning the study; 5) providing direct access between family caregivers and having greater involvement of a coach or clinical staff member to individualize caregiving information [50]; 6) consider having on-site technological staff; and 7) consider what caregivers are willing to pay for technological interventions such as the CSBI [29]. Overall, these findings provide support for the intervention content and approach, and are supportive of further refining this translated Caregiver Skill Building Intervention.

\section{Acknowledgements}

Phase 1: R42AG032159; Judith J. McCann, PhD, RN, Professor, Principal Investigator, Rush University College of Nursing, Chicago, IL; and Joel I Ehrlich, Chief Information Officer, Upstairs Solutions, Skokie, IL; Using Technology to Deliver Evidence-Based Interventions to Alzheimer Caregivers; 02/15/2012-12/31/2013.

Phase 2: R42AG032159; Carol J. Farran Credentials, DNSc, RN, FAAN, Professor, Principal Investigator, Rush University College of Nursing, Chicago, IL; and Peter Zurawski, Chief Information Officer, Grand Marketing Solutions, Libertyville, IL; Using Technology to Deliver Evidence-Based Interventions to Alzheimer Caregivers; 09/30/2014-08/31/2015.

\section{References}

1. Alzheimer's Association (2016) Alzheimer's disease facts and figures. Alzheimers Dement 12: 459-509.[Crossref]

2. Alzheimer's Association (2014) Alzheimer's disease facts and figures. Alzheimers Dement 10: e47-92.[Crossref]

3. Kasper JD, Freedman VA, Spillman BC (2011) Disability and Care Needs of Older Americans by Dementia Status: An Analysis of the 2011 National Health and Aging Trends Study. U S Department of Health and Human Services 2014.

4. Bouldin ED, Andresen E (2009) Caregiving Across the United States: Caregivers of Persons with Alzheimer's Disease or Dementia in 8 States and the District of Columbia; Data from the 2009 \& 2010 Behavioral Risk Factor Surveillance System.

5. Fisher GG, Franks MM, Plassman BL, Brown SL, Potter GG,et al. (2011) Caring for individuals with dementia and cognitive impairment, not dementia: Findings from The Aging, Demographics, and Memory Study. J Am Geriatr Soc 59: 488-494. [Crossref]

6. Seeher K, Low LF, Reppermund S, Brodaty H (2013) Predictors and outcomes for caregivers of people with mild cognitive impairment: a systematic literature review. Alzheimers Dement 9: 346-355.[Crossref]

7. Epstein-Lubow G, Guadiana B, Darling E, Hinckley M, Tremont G, et al. (2012) Differences in depression severity in family caregivers of hospitalized individuals with dementia and family caregivers of outpatients with dementia. Am J Geriatr Psychiatry20:815-819. [Crossref]

8. National Alliance for Caregiving and AARP (2015) Caregiving in the U.S.

9. Schulz R, Belle SH, CzajaS, Gitlin L, Wisniewski SR, et al. (2003) Introduction to 
the special section on resources for enhancing Alzheimer's caregiver health (REACH). Psychol Aging 18: 357-360. [Crossref]

10. Resnick B, Bellg AJ, Borrelli B, DeFrancesco C, Breger R, et al. (2005) Examples of implementation and evaluation of treatment fidelity in the BCC studies: Where we are and where we need to go. Ann Behav Med 29: 46-54. [Crossref]

11. Gouin J, Glaser R, Malarkey WB,Beversdorf D, Kiecolt-Glaser J (2012) Chronic stress, daily stressors, and circulating inflammatory markers. Health Psychol 31: 264-268. [Crossref]

12. vonKanel R, Mausbach BT, Dimsdale JE, Mills PJ, Patterson TL, et al. (2012) Effect of chronic dementia caregiving and major transitions in the caregiving situation on kidney function: A longitudinal study. Psychosom Med 74: 214-220. [Crossref]

13. Mausbach BT, Chattillion E, Roepke SK, Ziegler MG, Milic M, et al. (2012) A longitudinal analysis of the relations among stress, depressive symptoms, leisure satisfaction, and endothelial function in caregivers. Health Psychol 31: 433-440. [Crossref]

14. Chattillion EA, Mausbach BT, Roepke SK, von Kanel R, Mills PJ, et al. (2012) Leisure activities, caregiving demands and catecholamine levels in dementia caregivers. Psychol Health 27:1134-1149.

15. von Kanel R, Dimsdale JE, Mills PJ, Ancoli-Israel S, Patterson TL, et al. (2006) Effect of Alzheimer caregiving stress and age on frailty markers interleukin-6, C-reactive protein, and D-dimer. J Gerontol A Biol Sci Med Sci 61: 963-969.

16. Kiecolt-Glaser J, Glaser R, Gravenstein S, Malarkey WB, Sheridan J (1996) Chronic stress alters the immune response to influenza virus vaccine in older adults. Proc Natl Acad Sci U S A 93: 3043-3047. [Crossref]

17. Kiecolt-Glaser JK, Glaser R (1995) Psychoneuroimmunology and health consequences: data and shared mechanisms. Psychosom Med 57: 269-274.[Crossref]

18. Shaw WS, Patterson TL, Semple SJ, Ho S, Irwin MR, Hauger RL, et al. (1997) Longitudinal analysis of multiple indicators of health decline among spousal caregivers. Ann Behav Med 19: 101-109. [Crossref]

19. Vitaliano PP, Zhang J, Scanlan JM (2003) Is caregiving hazardous to one's physical health? A meta-analysis. Psychol Bull 129: 946-972.[Crossref]

20. Mausbach BT, Roepke SK, Ziegler MG, Milic M, von Kanel R, Dimsdale JE, et al. (2010) Association between chronic caregiving stress and impaired endothelial function in the elderly. J Am Coll Cardiol 55: 2599-2606. [Crossref]

21. Gitlin LN, Hodgson N (2015) Caregivers as therapeutic agents in dementia care: The context of caregiving and the evidence base for interventions. Family Caregiving in the New Normal San Diego, CA: Elsevier; pp. 305-353.

22. Knight BG, Lutzky SM, Macofsky-Urban F (1993) A meta-analytic review of interventions for caregiver distress: recommendations for future research. Gerontologist 33: 240-248.[Crossref]

23. Belle SH, Burgio L, Burns R, Coon D, Czaja SJ, Gallagher-Thompson D, et al. (2006) Enhancing the Quality of Life of Dementia Caregivers from Different Ethnic or Racial Groups. Ann Intern Med 145: 727-738.[Crossref]

24. Czaja SJ, Schulz R, Belle SH, Burgio LD, Armstrong N, Gitlin LN, et al. (2006) Data and safety monitoring in social behavioral interventions: The REACH II experience. Clin Trials 3: 107-118. [Crossref]

25. NikzadTerhune K, Anderson KA, La Bey L (2015)The impact of the Internet and Social Media on Caregiving. Family Caregiving in the New Normal San Diego, CA: pp. 269-89.

26. Bass DM, Judge KS, Lynn Snow A, Wilson NL, Morgan R, Looman WJ, et al. (2013) Caregiver outcomes of: partners in dementia care: Effect of a care coordination program for veterans with dementia and their family members and friends. $J$ Am GeriatrSoc 61:1377-1386. [Crossref]

27. Samus QM, Johnston DJ, Black BS, Hess E, Lyman C, Vavilikolanu A, et al. (2014) A multidimensional home-based care coordination intervention for elders with memory disorders: The maximizing independence at home (MIND) pilot randomized trial.Am J Geriatr Psychiatry 22: 398-414. [Crossref]

28. Whitlatch CJ, Judge K, Zarit SH, Femia E (2006) Dyadic intervention for family caregivers and care receivers in early-stage dementia. Gerontologist 46: 688-694. [Crossref]

29. Schulz R, Beach SR, Matthews JT, Courtney K, Dabbs, ADV, et al. (2016) Caregivers willingness to pay for technologies to support caregiving; Gerontologist 56: 817-829.

30. Nikzad-Terhume K, Anderson KA, La Bey L (2015) The Impact of the Internet and Social Media on Caregiving. Family Caregiving in the New Normal London, pp. 269-89.
31. Brennan PF, Moore SM, Smyth KA (1995) The effects of a special computer network on caregivers of persons with Alzheimer's disease. Nurs Res 44: 166-172.[Crossref]

32. Beauchamp N, Irvine AB, Seeley J, Johnson B (2005) Worksite-based internet multimedia program for family caregivers of persons with dementia. Gerontologist 45 : 793-801.[Crossref]

33. Ducharme F, Dube V, Levesque L, Saulnier D, Giroux F (2011) An online stress management training program as a supportive nursing intervention for family caregivers of an elderly person. Canadian Journal of Nursing Informatics 6: 13-44.

34. Beauchamp N, Irvine AB, Seeley J, Johnson B (2005) Worksite-based internet multimedia program for family caregivers of persons with dementia. Gerontologist 45 : 793-801.[Crossref]

35. Lai CK, Wong LF, Liu KH, Lui W, Chan MF, et al. (2013) Online and onsite training for family caregivers of people with dementia: Results from a pilot study. Int $J$ Geriatr Psychiatry 28: 107-08. [Crossref]

36. Marziali E, Garcia LJ (2011) Dementia caregivers' responses to 2 internet-based intervention programs. Am J Alzheimers Dis Other Demen 26:36-43. [Crossref]

37. Farran CJ, Gilley DW, McCann JJ, Bienias JL, Lindeman DA, et al. (2007) Efficacy of behavioral interventions for dementia caregivers. West J Nurs Res 29: 944-960. [Crossref]

38. Farran CJ, Gilley DG, McCann JJ, Bienias JL, Lindeman DA, et al. (2004) Psychosocia interventions to reduce depressive symptoms of dementia caregivers: A randomized clinical trial comparing two approaches. J Ment Health Aging 10: 337-350.

39. Farran CJ, Loukissa D, Perraud S, Paun O (2003) Alzheimer's disease caregiving information and skills. Part I: care recipient issues and concerns. Res Nurs Health 26 366-375.[Crossref]

40. Farran CJ, Loukissa D, Perraud S, Paun O (2004) Alzheimer's disease caregiving information and skills. Part II: Family caregiver issues and concerns. Res Nurs Health 27:40-51. [Crossref]

41. Perraud S,Farran CJ, Loukissa L, Paun, O (2013) Alzheimer's Disease Caregiving Information and Skills: Part III: Group Process Issues and Concerns. Res Nurs Health 27: 110-120. [Crossref]

42. Farran C (2014) Caregiver Skill Building Assessment Measure.

43. Lawton M, Moss M, Kleban M, Glicksman A, Rovine M (1991) A two-factor model of caregiving appraisal and psychological well-being. J Gerontol 46: 181-189. [Crossref]

44. Kohout FJ, Berkman LF, Evans DA, Cornoni-Huntley J (1993) Two shorter forms of the CES-D (Center for Epidemiological Studies Depression) depression symptoms index. J Aging Health 5: 179-193.[Crossref]

45. Watson D, Clark LA, Tellegan A (1988) Development and validation of brief measure of positive and negative affect: The PANAS scales. J PersSocPsychol 54:1063-1070. [Crossref]

46. Ehrlich J (2014) Program Evaluation for Web-Based Technology

47. Schreir M (2012) Qualitative Content Analysis in Practice. Thousand Oaks. Sage Publications, USA

48. Wikipedi (2010) Demographics of Chicago

49. Pew Research Center (2014) Older Adults and Technology.

50. Boots, LMM, de Vugt ME, van Knippenberg, RJM,Kempen, et al. (2014) A systematic review of Internet-based supportive interventions for caregivers of patients with dementia. Int J Geriatr Psychiatry 29: 331-344. [Crossref]

Copyright: (C2017 Farran CJ. This is an open-access article distributed under the terms of the Creative Commons Attribution License, which permits unrestricted use, distribution, and reproduction in any medium, provided the original author and source are credited. 